\title{
Response to Dietary Dilution in an Omnivorous Freshwater Turtle: Implications for Ontogenetic Dietary Shifts
}

\author{
Shannon J. McCauley \\ Karen A. Bjorndal ${ }^{*}$ \\ Archie Carr Center for Sea Turtle Research and Department \\ of Zoology, P.O. Box 118525, University of Florida, \\ Gainesville, Florida 32611
}

Accepted 7/23/98

\begin{abstract}
Several species of freshwater turtles in the family Emydidae undergo an ontogenetic dietary shift; as juvenile turtles mature, they change from a primarily carnivorous to a primarily herbivorous diet. It has been hypothesized that this shift results from an unfavorable ratio of gut capacity to metabolic rate that prevents small reptiles from processing adequate volumes of plant material to meet their energetic demands. Effects of dietary dilution on intake were evaluated in two size classes of red-eared sliders (Trachemys scripta elegans) to test whether small reptiles have a lower capacity to compensate for lowquality diets through increased intake than do larger conspecifics. Artificial diets with an inert diluent were offered to two size classes of turtles, and mass-specific intakes of dry matter, energy, and nitrogen were calculated. Both small $(28.7 \pm 4.9 \mathrm{~g}$ body mass, mean mass \pm SD) and large (1,230 $\pm 94 \mathrm{~g}$ body mass) turtles compensated for dietary dilution and maintained constant energy and nitrogen intakes on diets with lower energy content than common aquatic plants. Thus, body size did not affect the ability to respond to nutritional dilution, which suggests that processing limitations imposed by small body size do not constrain juveniles from adopting an herbivorous diet.
\end{abstract}

\section{Introduction}

Energetic differences related to body size have been hypothesized to be important in determining inter- and intraspecific differences in the dietary habits of many reptiles (Pough 1973,

\footnotetext{
${ }^{\star}$ To whom correspondence should be addressed. Address for correspondence: Department of Zoology, P.O. Box 118525, University of Florida, Gainesville, Florida 32611; e-mail: kab@zoo.ufl.edu.
}

Physiological and Biochemical Zoology 72(1):101-108. 1999. (C) 1999 by The University of Chicago. All rights reserved. 1522-2152/99/7201-97135\$03.00
1983; Wilson and Lee 1974). Additionally, observed ontogenetic dietary shifts in some reptiles have been attributed to a combination of these energetic differences and specific nutrient requirements for juveniles, including an increased need for calcium (Clark and Gibbons 1969) and nitrogen (White 1985; Parmenter and Avery 1990). These hypotheses propose that differences in mass-specific nutrient or energetic requirements affect the ability of animals to make use of resources that span a range of dietary concentrations.

The correlation between large body size and herbivory might occur because energetic constraints imposed on reptiles by increasing body size limit their ability to meet their metabolic requirements on a carnivorous diet (Clark and Gibbons 1969; Pough 1973, 1983; Wilson and Lee 1974; Parmenter and Avery 1990). Metabolic rates increase with body mass, although this relationship is reversed if considered on a mass-specific basis (Bennett and Dawson 1976). As a result, larger reptiles have higher total energetic demands than do small reptiles, a consequence of maintaining a greater total mass of muscle and other metabolizing tissue. A higher total muscle mass also means that larger turtles expend more energy in pursuing and capturing prey than do smaller turtles. Therefore, the net gain from foraging on mobile animal prey may be lower for large turtles than small turtles. To meet their higher energetic demands, larger turtles might rely on plant material both because of the higher energetic costs associated with capturing animal prey and because plant material is typically more abundant than animal prey (Pough 1973, 1983; Wilson and Lee 1974; Parmenter and Avery 1990). The hypothesis that large reptiles are forced to adopt herbivory implies that the costs of actively foraging for animal matter are too high relative to the energy gain such prey provide and therefore that large turtles better sustain their high total energy demands through herbivory.

An alternative hypothesis suggests that the unfavorable ratio of mass-specific energy requirements to gut capacity in smaller animals may limit their dietary intake and consequently decrease their ability to subsist on diets with low nutrient and energy concentrations, including diets composed primarily of plant material (Pough 1973, 1983; Wilson and Lee 1974; Demment 1983; Penry and Jumars 1987; Smith 1995). Small body size might function as a constraint to herbivory in reptiles if it limits their ability to process adequate volumes of nutritionally dilute diets, such as plants (Pough 1973, 1983; Wilson and Lee 1974). The extent to which small reptiles can increase intake in compensation for decreasing nutrient and energy concentrations has not been adequately explored. 
Dietary intake may be regulated by numerous factors, including prey availability, energetic requirements, environmental conditions, social behavior, and diet quality (Maynard et al. 1979; Parmenter 1981; Bjorndal 1986, 1987; Weston and Poppi 1987; Van Soest 1994). Although all of these factors may play a role in regulating intake, research suggests that, with access to palatable, nutritionally adequate food and under conditions of low environmental stress, animals regulate dietary intake to meet their energetic requirements (summarized in Weston and Poppi [1987]). Decreases in the digestible energy content of diets result in compensatory increases in dry mass intakes in horses (Laut et al. 1985), rabbits (Butcher et al. 1983), and ruminants (summarized in Baumgardt [1970]), as well as in slugs (Rueda et al. 1991), aquatic snails (Rollo and Hawryluk 1988), phytophagous insects (Simpson and Simpson 1990), and fish (Grove et al. 1978; Jobling 1980). These compensatory increases in dry mass intake resulted in constant digestible energy intakes and constant body mass gains in growing animals. However, these increases are constrained eventually by gut capacity, and herbivores fed very low-quality diets tend to decrease intake (Weston and Poppi 1987). As a result, the general relationship between diet quality and intake forms a curve in which decreasing diet quality leads to an initial increase in intake that compensates for decreasing digestible energy intake (Fig. 1). However, as diet quality continues to decrease, intake is reduced as palatability and the ability to extract nutrients essential for tissue metabolism decline (Weston and Poppi 1987). The relationship between intake and diet quality is likely to be affected by a variety of factors, including the animal's growth requirements, intestinal capacity, and reproductive condition (Baumgardt 1970; Butcher et al. 1983; Weston and Poppi 1987; Smith 1995).

The relationship between diet quality and intake can be examined experimentally by diluting the diet to alter systematically the concentrations of digestible energy or other nutrients in artificial diets. Previous studies have used water (Rueda et al. 1991), cellulose (Rollo and Hawryluk 1988), and kaolin (Jobling 1980; Coutteau et al. 1994) as inert diluents to explore the relationship between diet quality and intake. The extent to which animals can compensate for these inert diluents to maintain constant energy intakes determines their ability to meet their energetic demands on a low-quality diet and consequently their foraging ecology.

Slider turtles (Trachemys scripta) are a model system for testing hypotheses on the role of nutrient and energy concentrations in determining size-related dietary choices. Slider turtles are omnivores that forage on aquatic plants, invertebrates, and occasionally vertebrates (Ernst and Barbour 1989; Parmenter and Avery 1990). Opportunistic in their feeding habits, they will consume whatever is available but feed preferentially on animal matter (Parmenter and Avery 1990). However, like several other emydid turtles, they undergo an ontogenetic dietary shift involving an increased consumption of plant material by

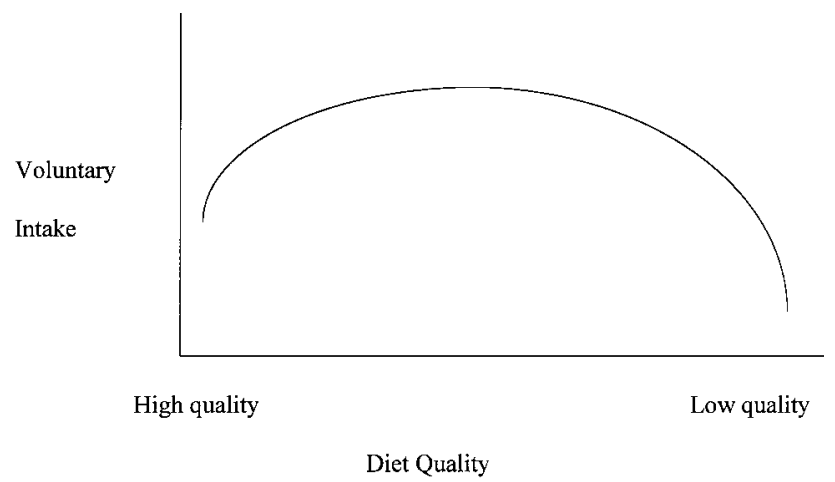

Figure 1. Theoretical relationship between diet quality and intake. The curve represents an approximation of the intake response by an individual organism to varying diet quality.

adults (Clark and Gibbons 1969; Hart 1983; Parmenter and Avery 1990). The observed dietary shift results in a change from a nutritionally concentrated diet (animal matter) to a nutritionally dilute diet (plant matter).

This study had two objectives. First, we tested the hypothesis that small body size functions as a processing constraint, thereby limiting the ability of juvenile slider turtles to maintain constant energy gains on nutritionally dilute diets. Second, we compared the ability of juveniles and adults to increase intake in response to decreasing nutrient and energy concentrations.

\section{Material and Methods}

\section{Animals and Housing Conditions}

Juvenile red-eared sliders (Trachemys scripta elegans) were obtained from a commercial source as hatchlings and maintained for approximately a year and a half in a large tank. They were fed a commercial turtle food ad lib. during this period. Eight juvenile turtles $(28.7 \pm 4.9 \mathrm{~g}$ body mass) were used in feeding trials. Six adult $T$. s. elegans (1,230 $\pm 94 \mathrm{~g}$ body mass) were obtained from a commercial turtle source and housed individually until the beginning of the feeding trial. Only male adult turtles were used to avoid effects of egg production on feeding behavior. During the feeding trials, turtles were housed separately in identical tanks. Tanks were lighted for $12 \mathrm{~h} \mathrm{~d}^{-1}$ with a 20-W full-spectrum fluorescent bulb (Vita-Lite) and a 75-W outdoor floodlight. Water in the tanks was changed daily after the completion of feeding and after food remaining in the tanks was collected. Water entered the tanks at $28^{\circ}-29^{\circ} \mathrm{C}$ and then equalized to room temperature and remained at $24^{\circ}-25^{\circ} \mathrm{C}$. This range of temperatures spans the range of preferred temperatures reported for T. s. elegans (Gatten 1974) and is comparable to those temperatures used in most other laboratory studies of $T$. s. elegans. 
Experimental Procedures

Feeding trials used four diets that were diluted to varying extents with an inert clay, kaolin (Sigma Chemical). Kaolin was used because of its success as a dietary diluent in other feeding studies (Grove et al. 1978; Jobling 1980; Coutteau et al. 1994). To test the safety of kaolin as a dietary diluent in turtles, we conducted a preliminary trial in which eight adult T. s. elegans were fed diets containing 50\% kaolin for $4 \mathrm{wk}$. The turtles were killed as part of a teaching lab at the end of the trial, and examination of their gastrointestinal tracts showed no indication of accumulation of kaolin along the gut or of tissue damage. We concluded that kaolin could be used safely as a dietary diluent in this study.

All diets were composed of gelatin (275 bloom; Fisher Scientific), fishmeal (Sigma Chemical), and a reptile mineral supplement (Reptocal). The four dietary treatments were designed to span a range of dilution down to a diet with $50 \%$ inert matter. The amount of gelatin relative to fishmeal was maintained at a $5.5: 1$ ratio, the highest proportion of fishmeal that maintained consistency in diet texture and stability for all four diets. The gelatin and fishmeal portions of all diets were assumed to have equivalent digestibilities because the diluent did not create structural barriers (i.e., in the manner of cell walls or lignin). The energy and nitrogen concentrations of these diets reflect their percent dilution (Table 1). The energy and nitrogen concentrations of all diets fall within the range of composition of common aquatic plants in the natural diet of T. scripta (Bjorndal 1991; Bjorndal and Bolten 1993). All diets were colored with red food coloring to stimulate feeding and to increase the visibility of orts (remaining food) to be collected.

A repeated-measures design was used to examine the intake of turtles on each of the four diets. Turtles were randomly assigned to a sequence of the four diets. Each phase consisted of an initial 5-d acclimation period, during which each turtle received the next experimental diet in its sequence. The acclimation period was followed by a 10 -d experimental period, during which intakes were measured and used to analyze each turtle's response to a given diet. The juvenile and adult trials were conducted sequentially. The juvenile trial was conducted from June 1 to August 1. The adult trial began August 2 and ended October 2.

Turtles were fed ad lib. for $4 \mathrm{~h}$ each day (0900-1300 hours for juveniles; 1000-1400 hours for adults). Following feeding, all remaining food (orts) was collected and dried at $60^{\circ} \mathrm{C}$. Weighed subsamples were taken from each diet daily, allowed to soak in water for the 4 -h feeding period, and then dried with the orts to determine the dry mass of each diet. The dry mass determined in this manner was used to calculate the dry mass of food offered.

Orts and daily diet samples were weighed following drying. Daily dry mass intake for each turtle was then calculated as
Table 1: Nutritional composition of experimental diets

\begin{tabular}{|c|c|c|c|c|}
\hline & \multicolumn{4}{|c|}{ Diet Dilution (\%) } \\
\hline & 0 & 15 & 35 & 50 \\
\hline Organic matter (\% DM) ...... & 97.2 & 83.1 & 64.8 & 51.2 \\
\hline Energy $\left(\mathrm{kJ} \mathrm{g}^{-1} \mathrm{DM}\right) \ldots \ldots \ldots \ldots$ & 21.9 & 18.6 & 13.8 & 10.2 \\
\hline Nitrogen (\% DM) .... & 16.0 & 13.9 & 10.2 & 7.3 \\
\hline
\end{tabular}

Note. DM is dry mass.

$$
\begin{aligned}
\text { Intake }= & {[\mathrm{WM} \text { offered }} \\
& \times(\mathrm{DM} \text { sample } / \mathrm{WM} \text { sample })]-\mathrm{DM} \text { orts, }
\end{aligned}
$$

where WM offered is the wet mass of food placed in an individual's tank, DM sample is the dry mass of the diet sample, WM sample is the wet mass of the diet sample, and DM orts is the dry mass of the remaining food, all expressed in grams. Treatment intakes were calculated on a mass-specific basis, averaged over the 10-d period for each turtle, and expressed as grams per kilogram body mass per day. The densities of all four diets were determined volumetrically. Densities did not differ among diets, indicating that an equal mass of each diet occupies an equal volume in the gastrointestinal tract of turtles. Therefore it is expected that analyses based on diet volume would yield the same results as presented here for diet mass.

Diets were analyzed for organic matter, energy, and nitrogen content. Dry mass percentages were measured by drying samples of each diet at $105^{\circ} \mathrm{C}$. Following dry mass measurements, samples were ashed in a muffle furnace at $500^{\circ} \mathrm{C}$ for $3 \mathrm{~h}$ to determine the percentage of organic matter. The energy content of the diets was determined using a standard bomb calorimetry procedure (Parr Instrument 1960). The concentration of nitrogen was measured using a block digester (Gallagher et al. 1975) and an automated Technicon analyzer (Hambleton 1977). More detailed methodology is in McCauley (1997).

\section{Statistical Analysis}

The effect of treatment on mean daily dry mass intake, mean daily energy intake, and mean daily nitrogen intake was analyzed for both size classes of turtles using separate repeatedmeasures general linear model (GLM) procedures with size class as a designated between-subjects effect. Energy and nitrogen intakes were determined on the basis of the analyzed diet concentrations of both nutrients, as these concentrations deviated slightly from their dietary percent dilution (Table 1). The repeated measures GLM allowed us to test for the effects of dietary dilution on dry mass intake, energy intake, and nitrogen intake and examine how the response differed between the two size classes of turtles. All statistical analyses were conducted using SPSS statistical software (SPSS 1996). Individual treatment effects on intake were analyzed using within-subjects simple con- 
trasts. The difference in mass-specific intake for juveniles and adults was compared with a between-subjects contrast. Expected mass-specific metabolic rates were calculated for each individual using the equation

$$
\mathrm{cm}^{3} \mathrm{O}_{2} /(\mathrm{g} \times \mathrm{h})=0.066 \mathrm{~g}^{-14}
$$

where metabolic rate is measured as the mass-specific hourly volume of oxygen consumption (Bennett and Dawson 1976).

\section{Results}

Diet had a significant effect on mass-specific dry mass intake (repeated-measures GLM; df $=3 ; F=11.527 ; P<0.001$ ). As predicted, intake increased with increasing dietary dilution ( Table 2). No diet by size class interaction was found in this test, indicating that adults and juveniles respond to dilution in the same way ( $\mathrm{df}=3 ; F=0.797 ; P=0.505)$.

Simple contrasts were used to compare mean mass-specific dry mass intakes for each diet. Contrasts compared intakes for the three less dilute diets to the diet diluted with 50\% inert matter, the most dilute diet. Intakes on the two least diluted diets (with $0 \%$ and 15\% kaolin, respectively) were significantly lower than intakes on the most dilute diet (with 50\% kaolin). Dry mass intakes for the two most dilute diets (with 35\% and $50 \%$ kaolin, respectively) were not significantly different (Table 2).

Size class had a significant effect on mass-specific dry mass intake on all experimental diets $(\mathrm{df}=1 ; F=14.72 ; P=0.003)$. Juveniles maintained consistently higher per gram dry mass intakes than adults, with mass-specific intakes being 2-3.4 times higher for juveniles than adults (Table 2).

Mean daily energy intake did not differ significantly among diets (repeated-measures GLM; $\mathrm{df}=3 ; F=0.569 ; P=0.640$; Table 2). The increases in dry mass intake were therefore ad- equate to maintain a constant level of energy gain. Energy intake was significantly different between the two size classes ( $\mathrm{df}=$ $1 ; F=15.391 ; P=0.003)$. The mass-specific energy intakes of juveniles were 1.8-3.3 times higher than for adults (Table 2). The expected mass-specific metabolic rates for juveniles averaged 2.7 times the mean expected metabolic rates for adults.

Mean daily nitrogen intake did not significantly differ among treatments (repeated measures GLM; $\mathrm{df}=3 ; F=0.400 ; P=$ 0.754; Table 2). Juveniles and adults differed significantly in their mean daily nitrogen intakes $(\mathrm{df}=1 ; F=16.986 ; P=$ 0.002). Mass-specific nitrogen intakes by juveniles were $2-3.3$ times higher than nitrogen intakes by adults (Table 2).

\section{Discussion}

\section{Nutrient Dilution and Ontogenetic Dietary Shift}

Juvenile and adult Trachemys scripta did not differ significantly in their response to dietary dilution. Both size classes were able to maintain constant energy and nitrogen intakes by increasing their dry mass intake in response to decreasing nutrient concentrations in experimental diets, and the responses of the two size classes paralleled each other. Higher mass-specific metabolic demands resulted in consistently higher mass-specific dry mass and energy intakes by the juvenile turtles. Juveniles maintained mass-specific dry mass intakes up to 3.4 times those of adults. However, the interaction between size class and intake was not significant, indicating that the two size classes do not differ in their ability to compensate for dietary dilution.

The experimental diets span a wide range of energy concentrations. A comparison of the energy content of the experimental diets (Table 1) to two common aquatic plants, Hydrilla verticillata (15.1 $\left.\mathrm{kJ} \mathrm{g}^{-1} \mathrm{DM}\right)$ and Spirodela polyrhiza $(18.1 \mathrm{~kJ}$ $\mathrm{g}^{-1} \mathrm{DM}$ ) (Bjorndal and Bolten 1992), indicates that the energy content of these two aquatic plants falls between the energy

Table 2: Mass-specific intakes for juveniles and adults on four experimental diets

\begin{tabular}{|c|c|c|c|c|c|c|}
\hline \multirow[b]{2}{*}{ Intake } & \multicolumn{6}{|c|}{ Diet Dilution (\%) } \\
\hline & 0 & & 15 & & 35 & 50 \\
\hline \multicolumn{7}{|l|}{ Juvenile $(n=8)$ : } \\
\hline Dry mass ....... & $2.9^{\mathrm{A}}$ & $\pm \quad 1.3$ & $2.8^{\mathrm{A}}$ & .52 & $3.6^{\mathrm{A}, \mathrm{B}} \pm$ & $5.9^{\mathrm{B}} \quad \pm$ \\
\hline Energy .......... & $62.0^{\mathrm{A}}$ & \pm 27 & $52.0^{\mathrm{A}}$ & \pm 10 & $48.0^{\mathrm{A}} \pm 18$ & \pm 20 \\
\hline Nitrogen ....... & $.46^{\mathrm{A}}$ & .20 & $.39^{\mathrm{A}}$ & .07 & $.36^{\mathrm{A}} \pm$ & $.42^{\mathrm{A}} \pm$ \\
\hline \multicolumn{7}{|l|}{ Adult $(n=4)$ : } \\
\hline Dry mass ...... & $.86^{\mathrm{A}}$ & .46 & $1.1^{\mathrm{A}}$ & .36 & $1.8^{\mathrm{A}, \mathrm{B}} \pm 1.2$ & $2.9^{\mathrm{B}} \pm 1.7$ \\
\hline Energy ......... & $19^{\mathrm{A}}$ & \pm 10 & $21^{\mathrm{A}}$ & \pm 7 & \pm 18 & \pm 18 \\
\hline Nitrogen ....... & $.14^{\mathrm{A}}$ & .07 & $.16^{\mathrm{A}}$ & .05 & $.18^{\mathrm{A}} \pm$ & $.21^{\mathrm{A}} \pm$ \\
\hline
\end{tabular}

Note. Values are mean \pm SD. Dry mass and nitrogen intakes are expressed as grams per kilogram of body mass per day. Energy intake is kiloJoules per kilogram of body mass per day. Within rows, means that share the same letter are not significantly different. 
concentrations of the diets diluted with $15 \%$ and $35 \%$ kaolin, respectively. Slider turtles consume both Spirodela sp. (Marchand 1942; Auth 1975; Hart 1983; Parmenter and Avery 1990) and $H$. verticillata (S. J. McCauley and K. A. Bjorndal, personal observation).

Digestibility was not measured for the experimental diets. Digestibility of the diets was assumed to be high because gelatin and fishmeal are very digestible and because the diluent did not form mechanical barriers that might lower digestibilities. If energy digestibilities are assumed to be $94 \%$, which is the upper range of energy digestibility reported in a reptile (summarized in Zimmerman and Tracy [1989]), energy gains for the adult turtles on the experimental diets span a range quite close to energy gains reported for adult T. scripta on S. polyrhiza and $H$. verticillata and well below energy gains on a carnivorous diet of Tenebrio larvae (Table 3). The extremely high energy gains on Tenebrio larvae probably reflect their high lipid concentration. No comparable data exist for juvenile T. scripta. However, in another freshwater turtle species (Pseudemys nelsoni, which is in the same subfamily as T. scripta), juveniles consuming $S$. polyrhiza had energy gains comparable to the juveniles in this study on the experimental diets: $53 \mathrm{~kJ} \mathrm{~kg}^{-1}$ body mass $\mathrm{d}^{-1}$ for P. nelsoni on S. polyrhiza (Bjorndal and Bolten 1992) and $51.3 \mathrm{~kJ} \mathrm{~kg}^{-1}$ body mass $\mathrm{d}^{-1}$ for T. scripta on the experimental diets. Adult P. nelsoni feeding on S. polyrhiza also had energy gains $\left(12 \mathrm{~kJ} \mathrm{~kg}^{-1}\right.$ body mass $\mathrm{d}^{-1}$; Bjorndal and Bolten 1992) similar to that of adult T. scripta in this study. Thus, the energy gains reported for juvenile P. nelsoni may give us an approximation of energy gains in juvenile T. scripta. With this assumption, it appears that the energy concentrations of plants in the diet of slider turtles fall within the range in which both juveniles and adults are able to compensate for variations in energy concentrations and maintain constant energy gains. If juveniles and adults differ in their capacity to compensate for dietary dilution by increasing intake to maintain constant energy gains, it occurs well below the energy concentrations of at least some of the common aquatic plants in the diets of both adult and juvenile sliders.
Nitrogen concentrations were higher in experimental diets (Table 1) than in either hydrilla (3.1\% DM) or S. polyrhiza (5.1\% DM) (Bjorndal and Bolten 1992). Estimated nitrogen gains in this study were also higher than reported nitrogen gains for adult $T$. scripta on herbivorous diets, although lower than on a carnivorous diet (Bjorndal 1991; Bjorndal and Bolten 1993). Consequently, we cannot determine the role of dietary nitrogen concentration in the ontogenetic dietary shift of T. scripta. However, Avery et al. (1993) examined the role of dietary crude protein concentrations $(=$ nitrogen concentration $\times 6.25)$ on ingestion rates in juvenile $T$. scripta of approximately three times the mass of the turtles used in this study. They found that, whereas crude protein concentrations alone did not have significant effects on ingestion rates, there was a significant interaction between crude protein content and temperature. Temperature and intake were positively correlated, and the rate of increase in intake between $28^{\circ} \mathrm{C}$ and $34^{\circ} \mathrm{C}$ was positively affected by dietary protein concentrations. At any given temperature, crude protein did not affect intake. Their results suggest that variations in nitrogen concentrations in our experimental diets did not affect intake given that all turtles were maintained at the same temperature.

Avery et al. (1993) did find that protein concentration could affect growth rates. In their study, turtles fed a $10 \%$ crude protein diet (the lowest protein concentration tested) grew more slowly than turtles fed on either a $25 \%$ or $40 \%$ crude protein diet. These results suggest that above some critical level of protein intake growth is not affected and additional protein consumed is converted to glucose to fuel energetic demands. The most dilute diet used in our experiment (50\% kaolin) had a crude protein concentration of $45 \%$, which is higher than the crude protein concentration of any of the diets used by Avery et al. (1993), suggesting that the protein concentrations of our diets would not produce differential growth rates or affect intake rates.

The ability of small T. scripta in this study to maintain constant energy intakes throughout a wide range of dietary dilution

Table 3: Comparison of energy gains for adult Trachemys scripta on different diets

\begin{tabular}{|c|c|c|}
\hline Diet & $\begin{array}{l}\text { Energy Gain } \\
\left(\mathrm{kJ} \mathrm{kg}^{-1} \text { body mass } \mathrm{d}^{-1}\right)\end{array}$ & Reference \\
\hline Spriodela polyrhiza ...... & 18.1 & $\begin{array}{l}\text { Bjorndal 1991; Bjorndal } \\
\text { and Bolten } 1992\end{array}$ \\
\hline Hydrilla verticillata ....... & 15.1 & $\begin{array}{l}\text { Bjorndal and Bolten } \\
1992\end{array}$ \\
\hline Tenebrio larvae ........... & 157 & Bjorndal 1991 \\
\hline Experimental diets ...... & $18.0-29.0$ & This study \\
\hline
\end{tabular}

Note. Energy gains on experimental diets assume $94 \%$ energy digestibilities, the upper range of energy digestibilities for reptiles (Zimmerman and Tracy 1989). 
suggests that they are capable of utilizing low-quality diets (energetically similar to plant material) efficiently. The parallels between juvenile and adult responses to decreasing diet quality in terms of energy and nitrogen indicate that, at these levels of dilution, large body size does not confer an advantage to subsisting on low-quality diets. Although it does not appear that the relationship between dietary energy concentrations and small body size is a critical factor in the ontogenetic dietary shift, the role of body size more generally is still unknown.

Several alternative hypotheses could explain the observed ontogenetic dietary shift, and the underlying selection pressures may affect juveniles, adults, or both. Juveniles may require higher concentrations of nutrients, such as calcium, than are typically found in plant material. These requirements may compel juveniles to adopt a carnivorous diet despite their ability to meet their energetic requirements on an herbivorous diet. Alternatively, perhaps neither juveniles nor adults are compelled to adopt their respective diets. Dietary differences may simply reflect change in the profitability of each diet as the costs of active foraging increase with body size. Juveniles may be capable of subsisting on plant-based diets but may maximize their net gains by pursuing and consuming invertebrate prey, whereas adults maximize net energetic gains by avoiding the costs of pursuing active prey and concentrating on consuming abundant plant material. Finally, the pressures driving this shift may be affecting large turtles rather than small. Whereas large body size results in higher total energy requirements, the costs of pursuing active prey increase with body size. These energetic factors, in conjunction with differences in the abundance and distribution of plant resources, as compared to animal prey, may force adults to adopt herbivorous foraging habits.

The possible role of prey distribution in driving a shift toward herbivory in the deep-water-dwelling adults requires further testing and should be examined by sampling invertebrates in these microhabitats. One test of particular interest would be to examine how prey distributions correlate with the extent or timing of ontogenetic dietary shifts. Hart (1983) found a dietary shift in T. s. elegans in southern Louisiana that was more gradual than a similar diet shift described in T. s. scripta in South Carolina (Clark and Gibbons 1969). If the distribution of invertebrate prey plays a role in forcing a dietary shift in large turtles, the timing of this transition might differ in ways that relate to invertebrate distributions in these habitats, with a more gradual transition reflecting a more even distribution of invertebrate prey. The total abundance of plant material relative to invertebrate prey might also be a factor driving large turtles to an increased reliance on herbivory. Throughout its range, $T$. scripta is associated with habitats abundant in aquatic vegetation (Moll and Legler 1971; Ernst and Barbour 1989; Parmenter and Avery 1990). The abundance of aquatic invertebrates may not be sufficient for large turtles to meet their high total energy requirements, causing adults to rely on the more abundant plant material in their habitat.
Implications for Herbivory in Reptiles

The observation that herbivory was rare in unspecialized lizard species with body masses less than $100 \mathrm{~g}$ and more common in species larger than $100 \mathrm{~g}$ as adults led to the hypothesis that large body size both required and permitted an herbivorous diet (Pough 1973; Wilson and Lee 1974). It was predicted that the energetic considerations that prevented small adult lizards from being herbivorous would result in the juveniles of "herbivorous" species relying on carnivory to meet their energetic requirements (Pough 1973). These hypotheses have been extended to explain similar dietary shifts in several emydid turtles including Graptemys pseudogeographica (Moll 1976), Chrysemys picta (Ernst and Barbour 1989), and T. scripta (Clark and Gibbons 1969; Hart 1983; Parmenter and Avery 1990). Our results neither confirm nor reject the hypothesis that large body size requires adult $T$. scripta to be herbivorous. Our data do, however, demonstrate that small turtles are capable of processing large volumes of low-quality diets to maintain constant energy intakes. This result suggests that, as long as digestibilities are unaffected by body size, small body size is not a constraint to herbivory.

Bjorndal (1997) outlined three mechanisms by which small reptiles might be able to meet their high mass-specific energy demands on nutritionally dilute herbivorous diets. Two proposed mechanisms - increased diet selectivity and the ingestion of smaller particles - appear to be important in enabling small reptiles to utilize plant material because they result in higher digestibilities of the diet. The ability of a number of small herbivorous reptiles, including a juvenile emydid turtle, to maintain high digestibilities while consuming large volumes of plant material (Mautz and Nagy 1987; Bjorndal and Bolten 1992) suggests that body size in reptiles need not be a factor in determining digestibilities of plant material. Increased passage rate, often a product of selecting higher body temperatures, is a third mechanism by which small reptiles might be able to meet high mass-specific metabolic demands on low-quality diets (Bjorndal 1997). Increased body temperatures may not, however, be a prerequisite of increased passage rates among juvenile reptiles (Troyer 1984; Mautz and Nagy 1987). Although we did not directly measure passage rates, juveniles daily processed significantly higher volumes of food on a mass-specific basis than did adults, suggesting that relatively high passage rates may have allowed juveniles to maintain constant energy gains on diets of varying quality.

Species that undergo ontogenetic dietary shifts provide an ideal system in which to examine the pressures affecting diet selection at different body sizes. Our results suggest that small body size does not limit the ability of reptiles to compensate for nutritionally dilute diets. Large individuals might be forced to adopt herbivory because of a combination of factors including the distribution and abundance of animal prey. Consequently, we would predict that small reptiles would be most 
likely to be herbivores under conditions of low prey densities or where factors independent of body size increase the costs of capturing active prey.

\section{Acknowledgments}

We thank A. Bolten, P. Eliazar, S. Schneider, and D. Wood for assistance with the feeding trials. Earlier versions of this manuscript were improved by comments from A. Bolten, H. Lillywhite, and L. McEdward. T. Wibbels graciously provided us with juvenile Trachemys scripta. Funding for this study was provided by a grant to K.A.B. and A. Bolten from the Marine Entanglement Research Program of the National Marine Fisheries Service through the Florida Cooperative Fish and Wildlife Research Unit (Research Work Order 118), the International Women's Fishing Association, the Galen C. Moses scholarship awarded by Bowdoin College, and the Archie Carr Center for Sea Turtle Research. All animal care was in full compliance with guidelines of the University of Florida Institutional Animal Care and Use Committee.

\section{Literature Cited}

Auth D.L. 1975. Behavioral ecology of basking in the yellowbellied turtle, Chrysemys scripta scripta (Schoepff). Bull Fla State Mus Biol Sci 20:1-45.

Avery H.W., J.R. Spotila, J.D. Congdon, R.U. Fisher, Jr., E.A. Standora, and S.B. Avery. 1993. Roles of diet protein and temperature in the growth and nutritional energetics of juvenile slider turtles, Trachemys scripta. Physiol Zool 66: 902-925.

Baumgardt B.R. 1970. Control of feed intake in the regulation of energy balance. Pp. 235-253 in A.T. Phillipson, ed. Physiology of Digestion and Metabolism in the Ruminant. Oriel, Newcastle upon Tyne.

Bennett A.F. and W.R. Dawson. 1976. Metabolism. Pp. 127-223 in C. Gans and W.R. Dawson, eds. Biology of the Reptilia. Vol. 5. Physiology A. Academic Press, New York.

Bjorndal K.A. 1986. Effect of solitary versus group feeding on intake in Pseudemys nelsoni. Copeia 1986:234-235.

- 1987. Digestive efficiency in a temperate herbivorous reptile Gopherus polyphemus. Copeia 1987:714-720.

- 1991. Diet mixing: nonadditive interactions of the diet items in an omnivorous freshwater turtle. Ecology 72: 1234-1241.

-1997. Fermentation in reptiles and amphibians. Pp. 199-230 in R.I. Mackie and B.A. White, eds. Gastrointestinal Microbiology. Vol. 1. Gastrointestinal Ecosystems and Fermentations. Chapman \& Hall, New York.

Bjorndal K.A. and A.B. Bolten. 1992. Body size and digestive efficiency in a herbivorous freshwater turtle: advantages of small bite size. Physiol Zool 65:1028-1039.
1993. Digestive efficiencies in herbivorous and omnivorous freshwater turtles on plant diets: do herbivores have a nutritional advantage? Physiol Zool 66:384-395.

Butcher C., M.J. Bryant, E. Owen, I. Leach, and D. H. Machin. 1983. The effect of dietary metabolizable energy concentration upon the pre- and post-weaning performance of growing rabbits. Anim Prod 36:229-236.

Clark D.B. and J.W. Gibbons. 1969. Dietary shift in the turtle Pseudemys scripta (Schoepff) from youth to maturity. Copeia 1969:704-706.

Coutteau P., N.H. Hadley, J.J. Manzi, and P. Sorgeloos. 1994. Effect of algal ration and substitution of algae by manipulated yeast diets on the growth of juvenile Mercenaria mercenaria. Aquaculture 120:135-150.

Demment M.W. 1983. Feeding ecology and the evolution of body size of baboons. Afr J Ecol 21:219-233.

Ernst C.H. and R.W. Barbour. 1989. Turtles of the World. Smithsonian Institution Press, Washington, D.C.

Gallagher R.N., C.O. Weldon, and J.G. Futral. 1975. An aluminum block digester for plant and soil analysis. Soil Sci Soc Am Proc 39:803-806.

Gatten R.E. 1974. Effect of nutritional status on the preferred body temperature of the turtles Pseudemys scripta and Terrapene ornata. Copeia 1974:912-917.

Grove D.J., L.G. Loizides, and J. Nott. 1978. Satiation amount, frequency of feeding and gastric emptying rate in Salmo gairdneri. J Fish Biol 12:507-516.

Hambleton L.G. 1977. Semiautomated method for simultaneous determination of phosphorous, calcium, and crude protein in animal feeds. J Assoc Off Anal Chem 60:845-852.

Hart D.R. 1983. Dietary and habitat shift with size of red-eared turtles (Pseudemys scripta) in a southern Louisiana population. Herpetologica 39:285-290.

Jobling M. 1980. Gastric evacuation in plaice, Pleuronectes platessa L.: effects of dietary energy level and food composition. J Fish Biol 17:187-196.

Laut J.E., K.A. Houpt, H.F. Hintz, and T.R. Houpt. 1985. The effects of caloric dilution on meal patterns and food intake of ponies. Physiol Behav 35:549-554.

Marchand L.J. 1942. A Contribution to the Knowledge of the Natural History of Certain Freshwater Turtles. MS thesis. University of Florida, Gainesville.

Mautz W.J. and K.A. Nagy. 1987. Ontogenetic changes in diet, field metabolic rate, and water flux in the herbivorous lizard Dipsosaurus dorsalis. Physiol Zool 60:640-658.

Maynard L.A., J.K. Loosli, H.F. Hintz, and R.G. Warner. 1979. Animal Nutrition. McGraw-Hill, New York.

McCauley S.J. 1997. Effects of Dietary Dilution in Chelonians: Implications for Their Ecology and Conservation. MS thesis. University of Florida, Gainesville.

Moll D. 1976. Food and feeding strategies of the Ouachita map 
turtle (Graptemys pseudogeographia ouachitensis). Am Midl Nat 96:478-482.

Moll E.O. and J.M. Legler. 1971. The life history of a neotropical slider, Pseudemys scripta (Schoepff), in Panama. Bull Los Angel Cty Mus Nat Hist Sci 11:1-102.

Parmenter R.R. 1981. Digestive turnover rates in freshwater turtles: the influence of temperature and body size. Comp Biochem Physiol 70A:235-238.

Parmenter R.R. and H.W. Avery. 1990. The feeding ecology of the slider turtle. Pp. 257-266 in J.W. Gibbons, ed. Life History and Ecology of the Slider Turtle. Smithsonian Institution Press, Washington, D.C.

Parr Instrument. 1960. Oxygen Bomb Calorimetry and Combustion Methods. Technical Manual 130. Parr Instrument, Moline, Ill.

Penry D.L. and P.A. Jumars. 1987. Modeling animal guts as chemical reactors. Am Nat 129:69-96.

Pough F.H. 1973. Lizard energetics and diet. Ecology 54: 837-844.

- 1983. Amphibians and reptiles as low energy systems. Pp. 141-188 in W.P. Aspey and S.I. Lustick, eds. Behavioral Energetics: The Cost of Survival in Vertebrates. Ohio State University Press, Columbus.

Rollo C.D. and M.D. Hawryluk. 1988. Compensatory scope and resource allocation in two species of aquatic snails. Ecology 69:146-156.

Rueda A.A., F. Slansky, Jr., and G.S. Wheeler. 1991. Compen- satory feeding response of the slug Sarasinula pleiba to dietary dilution. Oecologia 88:181-188.

Simpson S.J. and C.L. Simpson. 1990. The mechanisms of nutritional compensation by phytophagous insects. Pp. 111-160 in E.A. Bernays, ed. Insect-Plant Interactions. CRC, Boca Raton, Fla.

Smith F.A. 1995. Scaling of digestive efficiency with body mass in Neotoma. Funct Ecol 9:299-305.

SPSS. 1996. SPSS base 7.0 for Windows user's guide. SPSS, Chicago.

Troyer K. 1984. Diet selection and digestion in Iguana iguana: the importance of age and nutrient requirements. Oecologia 61:201-207.

Van Soest P.J. 1994. Nutritional Ecology of the Ruminant. 2d ed. Comstock, Ithaca, N.Y.

Weston R.H. and D.P. Poppi. 1987. Comparative aspects of food intake. Pp. 133-161 in J.B. Hacker and J.H. Ternouth, eds. The Nutrition of Herbivores. Academic Press, Orlando, Fla.

White T.C.R. 1985. When is a herbivore not a herbivore? Oecologia 67:596-597.

Wilson K.J. and A.K. Lee. 1974. Energy expenditure of a large herbivorous lizard. Copeia 1974:338-348.

Zimmerman L.C. and C.R. Tracy. 1989. Interactions between environment and ectothermy and herbivory in reptiles. Physiol Zool 62:374-409. 